American J. of Engineering and Applied Sciences 1 (3): 204-209, 2008

ISSN 1941-7020

(C) 2008 Science Publications

\title{
Determination of Rheological Properties of Bio Mastic Asphalt
}

\author{
R. Muniandy, H. Jafariahangari, R. Yunus and S. Hassim. \\ Department of Civil Engineering, \\ University Putra Malaysia, 43400 UPM, Serdang, Selangor, Malaysia
}

\begin{abstract}
Due to the high oil prices the price of asphalt binder has increased tremendously. This scenario has warranted demand for higher viscosity cheaper asphalt for pavement construction. A study was conducted to take advantage of the Empty Fruit Bunch (EFB) of Date and Oil Palm trees (which are considered as waste) to produce cellulose fiber to be used as additives in the asphalt binder. If these EFB's could be beneficially utilized in any application, it would reduce the load on the nation's landfills and at the same time reducing the cost of road construction. A total of 11 blends were prepared that consisted of 5 blends with date palm fiber, 5 blends with oil palm fiber and one control sample that contained no fibers. The samples were evaluated using Dynamic Shear Rheometer (DSR) equipment in accordance with the superpave Strategic Highway Research Program (SHRP) requirements. The neat asphalt binders (Unaged), Rolling Thin Film Oven (RTFO) aged and Pressure Ageing Vessel (PAV) samples were then measured for phase angle, shear strain and complex shear modulus and then evaluated in accordance with SHRP requirements. The results indicated that the fibers enhanced the rheological performance of Bio Mastic Asphalt (BMA) blends. The control sample which was categorized as PG58 was enhanced to PG76 with $0.375 \%$ date palm fiber. The oil palm has also improved the blend up to PG70 with $0.3 \%$ oil palm fiber.
\end{abstract}

Key words: Bio Mastic Asphalt (BMA), date palm fiber, oil palm fiber, asphalt cement stabilizer, waste materials

\section{INTRODUCTION}

Fibers are being used in the pavement construction industry, especially in gap graded mixes such as Stone Mastic Asphalt (SMA), Open Graded Friction Course (OGFC) mixtures to improve the draindown, Runoff and the fatigue life of the asphalt concrete. Fibers have been grouped fibers in two categories: first the high modulus of elasticity fibers such as glass, asbestos and carbon fibers which are less suitable for random dispersion in asphaltic concrete. Glass and carbon are venerable to damage during mixing and compaction while asbestos is very costly and hazardous. Secondly low modulus elasticity fibers on the other hand are more versatile as it can be easily dispersed in a variety of mixes. Examples of low modulus of Elasticity fibers are natural and synthetic fibers. In this research, natural fiber such as Date and oil Palm Fiber is studied. Low modulus Elasticity fibers are more convenient for pavement construction because during the construction the fibers are exposed to heavy loads for compaction and the sharp angular stones could damage the fibers therefore if high elasticity modulus fibers are used they could be vulnerable to damage and breaking ${ }^{[1]}$.

Malaysian have used cellulose oil palm fiber to produce stone matrix asphalt (SMA) mixes. The results of their study revealed that the fibers not only improve of draindown of the mix, but also enhanced the resistance of the mix to resist fatigue cracking. A remarkable enhancement in the fatigue resistance, with a fiber range of 0.6 percent by the weight of total mix was observed. In their studies cellulose fibers were obtained through selective processes and the chemically pulped fibers showed higher potential for resisting fatigue and improving draindown. The Malaysian Cellulose Oil Palm Fiber (COPF) not only improved the viscosity of the unmodified asphalt and at the same time improved the tensile strength and the stiffness of SMA Mix. In terms of indirect tensile strength, the maximum load achieved in their study was improved by 325 at $0.6 \%$ fiber content compared to without fiber. Additionally, it was observed that the crack mender length was reached its peak with a cellulose fiber proportion of $0.6 \%$ by the weight of total $\mathrm{mix}^{[1]}$.

Corresponding Author: H. Jafariahangari, Department of Civil Engineering, University Putra Malaysia, 43300 Serdang, Selangor, Malaysia Tel/Fax: +603-89466373 
Hassan and Jabri ${ }^{[2]}$ evaluated the effect of two types of organic fibers (date palm and textile fibers), Styrene Butadiene Rubber (SBR) polymer on the Open Graded Friction Course (OGFC) mix properties. The effect of adding the fibers and SBR polymer on the raveling potential and draindown of the mixes were considered their study. The use of textile fibers in the mix resulted in a significant reduction in draindown at high asphalt content compared with other mixes. The addition of polymer to textile fibers in the same mix did not result in a significant reduction in draindown $\mathrm{n}^{[2-4]}$.

\section{MATERIALS AND METHODS}

Traditionally the 80/100 binder (unmodified) used in Malaysia is unable to resist the heavy loads from trucks. Unmodified binder does not have a good fatigue performance which is considered the most predominant mode of failure. The fibers improved the service properties of the SMA mixes by forming micromesh netting in the asphalt mix to prevent drain down of asphalt and at the same time improve the stability and durability of the pavement $\operatorname{mix}^{[1]}$. The increased viscosity is due to the micromesh netting formed in the binder that is just a physical reinforcement of the binder, unlike polymer which changes the molecular chain of the binder and increases the viscosity.

In this study a 80/100 penetration grade (PG58 equivalent) soft base asphalt was modified by adding different proportions of cellulose date and oil palm fiber and the rheological properties of the BMA were evaluated. The master curves for shear modulus, phase angle, shear strain, viscosity, rutting and fatigue parameters have been prepared over a very large temperature (frequency) range. The results were then evaluated with the SHRP requirements. Different BMA blends with different fiber contents were then classified into Performance Grade (PG) indicating each fiber content will lead into certain Performance Grade (PG).

Bio mastic asphalt production: Typical $80 / 100$ penetration grade asphalt binder with ring and ball softening point $\left(\mathrm{T}_{\mathrm{R} \text { and } \mathrm{B}}\right)=46^{\circ} \mathrm{C}$, penetration $=86 \mathrm{dmm}$ and the viscosity of $0.254 \mathrm{~Pa} . \mathrm{S}$ at $135^{\circ} \mathrm{C}$ and $0.100 \mathrm{~Pa} . \mathrm{s}$ at $165^{\circ} \mathrm{C}$ was stabilized through the addition of different amount by the weight of total mix with Cellulose Oil Palm Fiber (COPF) and Cellulose Date Palm Fiber (CDPF). The blending procedure was carried out as follows: containers of approximately $500 \mathrm{~mL}$ were filled with $250 \mathrm{~g}$ of asphalts. The asphalt samples were heated up in the oven to the mixing temperature which was $153.7^{\circ} \mathrm{C}$, in this temperature the asphalt binder has the viscosity of $0.17 \mathrm{~Pa}$.s that is required viscosity by SHRP for blending the asphalt binder with the aggregates in order to produce asphalt concrete.

After achieving the required blending temperature in the oven the asphalt binder container was placed in a bigger container that was filled granite filler in order to prevent heat lost via the conductivity, the set up was then placed on a hot plate to restore the heat lost. When the asphalt cement reached $153.74 \pm 1^{\circ} \mathrm{C}$, a stirrer was dipped into the container for blending the fiber and asphalt cement. The fibers were added gradually $(1 \pm 0.001$ gram every $5 \mathrm{~min})$ while keeping the temperature within the range of $153.74 \pm 1^{\circ} \mathrm{C}$. The stirrer was set to 700 RPM for the first two proportions of fibers added (first two grams), to reduce splashing and decreasing the air bubbles trapped inside the samples. After 10 min into the test the stirrer was set to 900 RPM while adding the third and the fourth proportion, after adding the fifth proportion of fiber (fifth gram) the speed of stirring was set to 1500 RPM. When the fiber addition was completed the blend was stirred for 30 min with a speed of 2000 RPM, except for the first blend which consisted of $0.075 \%$ (3.12 gram) fiber by the weight of total mix which was stirred for $30 \mathrm{~min}$ after the addition of the last portion of 0.12 gram with speed of 1500 RPM. Total of 11 blends were made that consisted of 5 blends with date palm fiber $(0.075$, $0.150,0.225,0.300$ and $0.375 \%), 5$ blends with oil palm fiber $(0.075,0.150,0.225,0.300$ and $0.375 \%)$ and the control sample that consisted of no fiber. Table 1 shows the amount of fibers used for bending.

Bio mastic asphalt rheological properties: The rheological properties of the blend was then evaluated by using the Dynamic Shear Rheometer (DSR) which is Designed to precisely measure stresses and strains of various materials under oscillatory, steady shear and repeated loads at various temperatures. The tests were carried out on control stress mode in accordance with AASHTO TP5-93. Controlled stress rheometers apply a sinusoidal varying stress and determine the resulting strain $^{[5]}$. The DSR used two different sized parallel plate sets for evaluating asphalt binder: 8-mm diameter plates (used for PAV-aged asphalt) and $25 \mathrm{~mm}$ diameter plates (used for RTFO-aged asphalt).

\begin{tabular}{lc} 
Table 1: Amount of fibers used to blend with asphalt binder \\
\hline Fiber content (\%) & Weight of fiber $(\mathrm{g})$ \\
\hline 0.00 & 0.00 \\
0.075 & 3.12 \\
0.150 & 6.24 \\
0.225 & 9.36 \\
0.300 & 12.48 \\
0.375 & 15.60 \\
\hline
\end{tabular}


The loading angular frequency was set to $10 \mathrm{rad}$ $\sec ^{-1}(1.59 \mathrm{~Hz})$, The $10 \mathrm{rad} \mathrm{sec}^{-1}$ angular frequency corresponds, with sinusoidal loading, to a 0.1 second loading time, where loading time $(\mathrm{t})$ is determined from the relationship $\mathrm{t}=(2 \pi f)^{-1}$. The $0.1 \mathrm{sec}$ loading time represents the loading time within a pavement structure resulting from the pass of a truck tire traveling at 50 $\mathrm{mph}\left(90 \mathrm{Km} \mathrm{h}^{-1}\right)^{[6]}$.

The target shear stress depending on type of asphalt was set to $0.12 \mathrm{kPa}$ for neat asphalt cement, $0.22 \mathrm{kPa}$ for RTFO aged asphalt cement and $50 \mathrm{kPa}$ for PAV aged asphalt binder. The rheological properties of the BMA samples were evaluated in a temperature range of $30^{\circ} \mathrm{C}$ to $80^{\circ} \mathrm{C}$ in order to classify each BMA in Performance Grade (PG) category. This way rutting and fatigue parameters were measured and compared with the Superpave requirements.

A higher $G^{*}$ (complex modulus) and a lower $\delta$ (phase angle) are desired for rutting resistance. An asphalt with a high $\mathrm{G}^{*}$ is stiffer and provides increased resistance to deformation. Asphalt exhibiting a lower $\delta$ has a greater elastic component, thus allowing more of the total deformation to be recovered. The relationship $\mathrm{G}^{*} / \sin \delta$ was chosen as the parameter for SHRP specifications with respect to rutting. This relationship follows the rationale that a binder with a high $\mathrm{G}^{*}$ value is stiffer, which increases its resistance to deformation and a binder with a low $\sin \delta$ value is more elastic, whereby its ability to recover part of the deformation is increased. The minimum limit set by superpave for $\mathrm{G}^{*} / \sin \delta$ for unaged asphalt testing is $1.0 \mathrm{kPa}$ and the minimum limit of $\mathrm{G}^{*} / \mathrm{sin} \delta$ for RTFO residue is 2.2 $\mathrm{kPa}$.

Fatigue cracking is the primary pavement distress at intermediate service temperatures ${ }^{[5]}$. The $\mathrm{G}^{*} \sin \delta$ relationship was therefore selected as a parameter for the SHRP specification. By limiting the $G^{*} \sin \delta$ parameter, decreasing $\mathrm{G}^{*}$ and/or $\sin \delta$, the energy dissipated per cycle is limited as well. This limiting parameter follows the rationale that a binder with a low $\mathrm{G}^{*}$ is softer, which allows it to deform without developing high stresses and a binder with a low $\sin \delta$ will be more elastic, which enables the pavement structure to return to its original condition without dissipating energy. A maximum limit of $5000 \mathrm{kPa}$ was established for the $\mathrm{G}^{*} \times \sin \delta$ parameter by SHRP. The RTFO and PAV tests were respectively carried out in accordance with AASHTO T240 and AASHTO PP1. Total of 33 DSR tests with varying temperatures were carried out, eleven DSR tests on the BMA (5 blends with COPF, 5 blends with CDPF and one control sample with no fiber), eleven DSR tests on RTFO aged
BMA blends and eleven DSR tests on the PAV aged BMA blends.

\section{RESULTS AND DISCUSSION}

Using the DSR equipment the rheological properties of the blend were evaluated by measuring the complex shear modulus $\mathrm{G}^{*}$, phase angle $\delta$ and percent shear strain. Figure 1 and 2 respectively show the complex shear modulus for various compositions of oil and date palm fiber. There is an enhancement in term of complex shear modulus for blends containing cellulose fiber compare to the control sample that contains no fiber.

This is the first symptom of scarce compatibility between the cellulose fiber and the base asphalt. It is been observed that the cellulose date palm fiber (CDPF) has a greater complex shear modulus that the cellulose oil palm fiber (COPF) at temperatures higher than $60^{\circ} \mathrm{C}$ but at lower temperatures $\left(30^{\circ} \mathrm{C}\right)$ samples containing

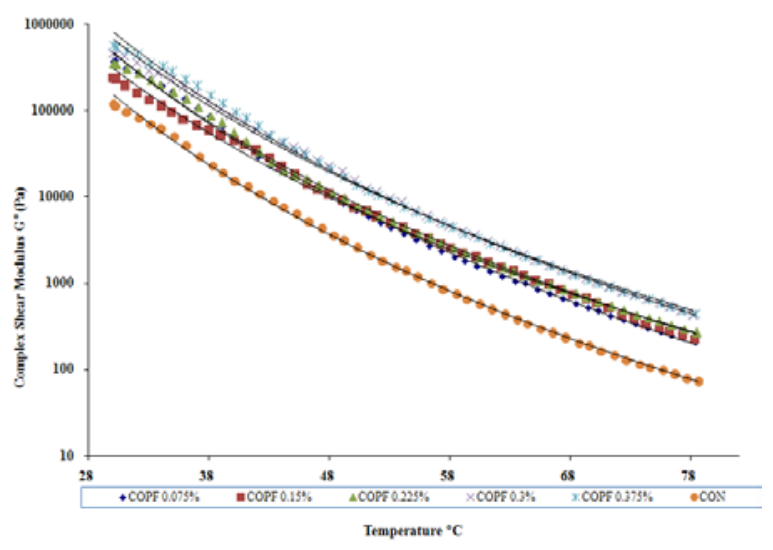

Fig. 1: Complex shear modulus for BMA with COPF



Fig. 2: Complex shear modulus for BMA with CDPF 


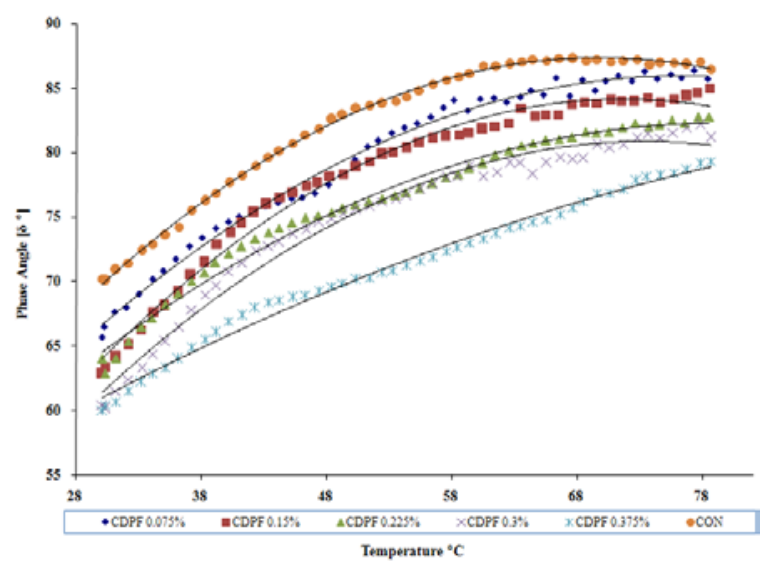

Fig. 3: Phase angle for BMA with CDPF.

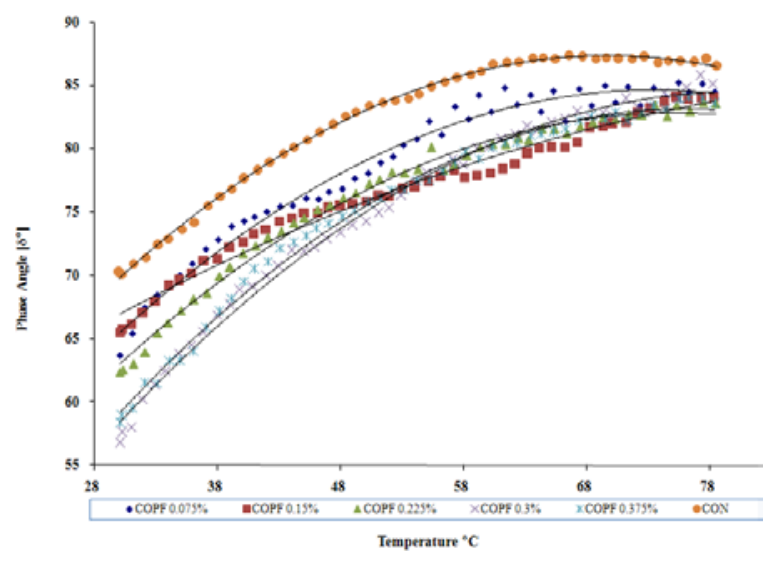

Fig. 4: Phase angle for BMA with COPF.

fibers compare to control sample does not make much of a different. Blends containing $0.3 \%$ of $\mathrm{COPF}$ is performing almost the same as samples with $0.375 \%$ of COPF in term of complex shear modulus, this could be an indication of $0.3 \%$ of optimum fiber for the COPF blends and $0.375 \%$ for the CDPF that is standing higher than other date palm fiber content in term of complex shear modulus.

Figure 3 and 4 below display the changes of the phase angle with the variation of the temperature for the blends containing various percentages of CDPF and COPF. For the control sample that contains no fiber the curve is very smooth but as for blends containing fiber in some cases the phase angel has an unstable magnitude. Date and oil palm fiber blends with $0.075 \%$ fiber at $60^{\circ} \mathrm{C}$ and above starts to show an unpredicted variation in the phase angle, this could be due to engagement and disengagement of the micromesh inside the blends. With the increase of the fiber inside the blend this unpredicted behavior seem to become

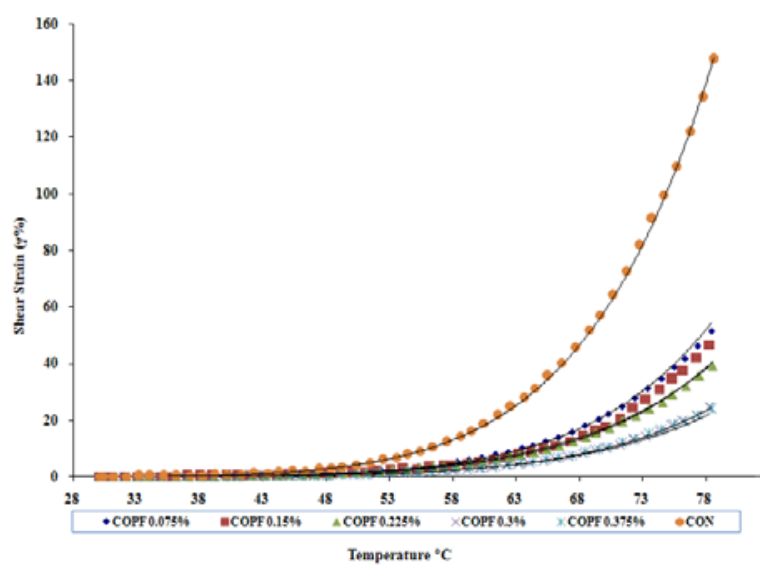

Fig. 5: Shear Strain for BMA with COPF

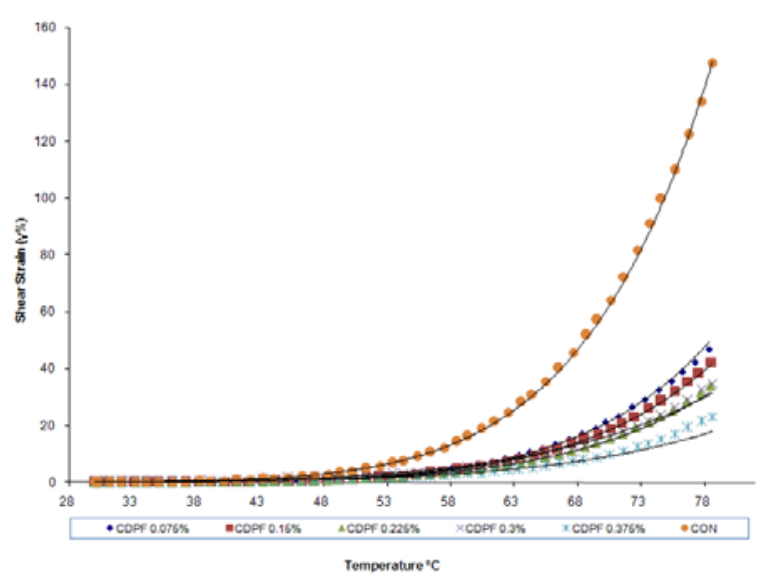

Fig. 6: Shear Strain for BMA with CDPF

less which could because of all the individual micromeshes formed are chained together. The blend containing $0.375 \%$ CDPF shows a great decrease in the phase angle on the contrary the same percentage of COPF does not display a good performance in term of the phase angle. With the increase of the fiber in the blends containing date palm fiber the phase angle is decreasing in a trend, but as for the oil palm fiber is performing slightly lower than the date palm fiber. The gap that could be seen in between 0.3 and $0.375 \%$ of fiber for the date palm could not be observed for the oil palm fiber. For the oil palm fiber 0.3 and $0.375 \%$ of fiber content are almost performing in the same manner.

Therefore this could be another indication that the optimum fiber content for the COPF blends could be $0.3 \%$ and for the CDPF could go up to $0.375 \%$.

Figure 5 and 6 below show the shear strain in percent for the oil and date palm fiber respectively. There is a great enhancement for the shear strain for the 
blends contain fibers compare to the control sample especially for temperatures over $60^{\circ} \mathrm{C}$ that is high pavement temperature in summer this difference in the shear strain starts to grow bigger. Again for the oil palm fiber blends there seem to be not much of a difference for blends with $0.3 \%$ and $0.375 \%$ of fiber content. This could also be another indication of optimum fiber content of $0.3 \%$ for COPF blend but as for the date palm blends, blend with fiber content of $0.375 \%$ has the best performance in term of shear strain. Overall the oil palm blends show a higher shear strain compared to date palm blends. This reason could be because of the pulping method used in producing the fibers. Date palm fiber was produced using the chemical pulping method but the oil palm fibers were produced using the RMP method. In the chemical pulping the product is pure cellulose but in the RMP method the obtained product not only contains cellulose but also contains other organic compositions.

A power trend line was chosen to best fit the performance curves of unaged rutting behavior, RTFO rutting behavior and the PAV fatigue behavior. From the equation of the power trend line the behavior for rutting and fatigue was studied and the failure point to meet the SHRP requirements was obtained. SHRP requires the unaged rutting parameter to be greater than $1000 \mathrm{~Pa}\left(\mid \mathrm{G}^{*} / / \mathrm{SIN}(\delta)>1000 \mathrm{~Pa}\right)$, the RTFO rutting parameter to be greater than $2200 \mathrm{~Pa}\left(\mid \mathrm{G}^{*} / / \mathrm{SIN}\right.$ $(\delta)>2200 \mathrm{~Pa}$ ) and the PAV aged fatigue parameter to be less than $5000 \mathrm{kPa}\left(\left|\mathrm{G}^{*}\right| \times \operatorname{SIN}(\delta)<5000 \mathrm{kPa}\right)$. The maximum temperature for the unaged and RTFO aged blends to meet the rutting parameters and the minimum temperature for the PAV aged blends to meet the SHRP fatigue requirements are shown in the Table 2 .

In the Table 2 below y is the calculated rutting or fatigue parameter in $\mathrm{Pa}$ and $\mathrm{T}$ is the temperature in ${ }^{\circ} \mathrm{C}$. By placing the required y magnitude by SHRP the maximum or minimum temperature is obtained. As an example by placing $\mathrm{y}=1,2.2$ and $5000 \mathrm{kPa}$ in equations obtained respectively for the unaged rutting parameter, RTFO aged rutting parameter and the PAV aged fatigue parameter the maximum temperature to failure for the unaged and the RTFO aged and the minimum temperature to failure for the PAV aged blends are obtained. After comparing the obtained temperatures with the SHRP (superpave) requirements, the BMA is classified into Performance Grade (PG) category. It can be clearly observed that the binder containing no fiber is classified as PG58 but with adding $0.375 \%$ date palm fiber the performance grading of the binder is enhanced by 3 steps in PG grading system, the performance has increased up to PG76 with the date palm fiber but as for the oil palm fiber the enhancement was not as much as the date palm fiber and the maximum enhancement was 2 steps in PG system (Fig. 7 and 8 ).

Table 2: BMA Performance Grade (PG) system

Percent fiber by the weight of total mix

\begin{tabular}{|c|c|c|c|c|c|c|c|c|c|c|c|}
\hline & \multirow[b]{2}{*}{ Control } & \multicolumn{5}{|c|}{ Cellulose Oil Palm Fiber (COPF) } & \multicolumn{5}{|c|}{ Cellulose Date Palm Fiber (CDPF) } \\
\hline & & $0.075 \%$ & $0.15 \%$ & $0.225 \%$ & $0.3 \%$ & $0.375 \%$ & $0.075 \%$ & $0.15 \%$ & $0.225 \%$ & $0.3 \%$ & $0.375 \%$ \\
\hline \multicolumn{12}{|c|}{ Failure temperature $\left({ }^{\circ} \mathrm{C}\right)$ to satisfy $\mathrm{SHRP}$ requirement unaged sample $\left[\left|\mathrm{G}^{*}\right| / \mathrm{SIN}(\delta)\right]>1000 \mathrm{~Pa}$} \\
\hline $\begin{array}{l}\text { Rutting behavior } \\
\text { equation (unaged) }\end{array}$ & $\begin{array}{l}\mathrm{y}=7 \times 10^{16} \\
\times \mathrm{T}^{-7.85}\end{array}$ & $\begin{array}{l}\mathrm{y}=4 \times 10^{17} \\
\times \mathrm{T}^{-7.97}\end{array}$ & $\begin{array}{l}7 y=3 \times \\
10^{17} \times \mathrm{T}^{-7.90}\end{array}$ & $\begin{array}{l}\mathrm{y}=3 \times 10^{18} \\
\times \mathrm{T}^{-8.46}\end{array}$ & $\begin{array}{l}y=9 \times \\
10^{16} \times T^{-7.47}\end{array}$ & $\begin{array}{l}y=5 \times \\
10^{17} \times T^{-7.87}\end{array}$ & $\begin{array}{l}y=6 \times \\
10^{17} \times T^{-8.10}\end{array}$ & $\begin{array}{l}y=3 \times \\
10^{16} \times T^{-7.35}\end{array}$ & $\begin{array}{l}y=1 \times \\
10^{16} \times T^{-7.04}\end{array}$ & $\begin{array}{l}y=9 \times \\
10^{13} \times T^{-5.93}\end{array}$ & $\begin{array}{l}y=2 \times \\
10^{14} \times T^{-6.00}\end{array}$ \\
\hline $\begin{array}{l}\text { Unaged binder } \\
\text { maximum failure } \\
\text { temperature }\end{array}$ & $58.04^{\circ} \mathrm{C}$ & $67.94^{\circ} \mathrm{C}$ & $68.00^{\circ} \mathrm{C}$ & $67.52^{\circ} \mathrm{C}$ & $73.80^{\circ} \mathrm{C}$ & $73.74^{\circ} \mathrm{C}$ & $66.75^{\circ} \mathrm{C}$ & $68.17^{\circ} \mathrm{C}$ & $70.24^{\circ} \mathrm{C}$ & $70.35^{\circ} \mathrm{C}$ & $76.47^{\circ} \mathrm{C}$ \\
\hline \multicolumn{12}{|c|}{ Failure temperature $\left({ }^{\circ} \mathrm{C}\right)$ to satisfy SHRP requirement for $\mathrm{RTFO}$ aged sample $\left[\left|\mathrm{G}^{*}\right| / \operatorname{SIN}(\delta)\right]>2200 \mathrm{~Pa}$} \\
\hline $\begin{array}{l}\text { Rutting behavior } \\
\text { equation } \\
\text { (RTFO aged) }\end{array}$ & $\begin{array}{l}y=9 \times \\
10^{14} \times T^{-6.41}\end{array}$ & $\begin{array}{l}y=1 \times \\
10^{18} \times T^{-7.91}\end{array}$ & $\begin{array}{l}y=2 \times \\
10^{18} \times T^{-8.14}\end{array}$ & $\begin{array}{l}y=5 \times \\
10^{16} \times T^{-7.22}\end{array}$ & $\begin{array}{l}y=4 \times \\
10^{18} \times T^{-8.19}\end{array}$ & $\begin{array}{l}y=3 \times \\
10^{15} \times T^{-6.51}\end{array}$ & $\begin{array}{l}y=4 \times \\
10^{18} \times T^{-8.31}\end{array}$ & $\begin{array}{l}y=3 \times \\
10^{18} \times T^{-8.19}\end{array}$ & $\begin{array}{l}y=8 \times \\
10^{16} \times T^{-7.25}\end{array}$ & $\begin{array}{l}y=2 \times \\
10^{17} \times T^{-7.41}\end{array}$ & $\begin{array}{l}y=7 \times \\
10^{14} \times T^{-5.86}\end{array}$ \\
\hline $\begin{array}{l}\text { RTFO aged binder } \\
\text { maximum failure } \\
\text { temperature }\end{array}$ & $64.79^{\circ} \mathrm{C}$ & $71.29^{\circ} \mathrm{C}$ & $68.81^{\circ} \mathrm{C}$ & $70.78^{\circ} \mathrm{C}$ & $72.98^{\circ} \mathrm{C}$ & $73.11^{\circ} \mathrm{C}$ & $68.60^{\circ} \mathrm{C}$ & $70.46^{\circ} \mathrm{C}$ & $74.2^{\circ} \mathrm{C}$ & $76.52^{\circ} \mathrm{C}$ & $91.82^{\circ} \mathrm{C}$ \\
\hline \multicolumn{12}{|c|}{ Failure temperature $\left({ }^{\circ} \mathrm{C}\right)$ to satisfy SHRP requirement $\left[\left|\mathrm{G}^{*}\right| \times \operatorname{SIN}(\delta)\right]<5000 \mathrm{kPa}$} \\
\hline $\begin{array}{l}\text { Fatigue behavior } \\
\text { equation } \\
\text { (PAV aged) }\end{array}$ & $\begin{array}{l}y=1 \times 10^{20} \\
\times T^{-9.26}\end{array}$ & $\begin{array}{l}y=1 \times 10^{19} \\
\times T^{-8.75}\end{array}$ & $\begin{array}{l}{ }^{9} y=6 \times \\
10^{21} \times T^{-9.95}\end{array}$ & $\begin{array}{l}y=5 \times \\
10^{20} \times T^{-9.36}\end{array}$ & $\begin{array}{l}y=1 \times 10^{20} \\
\times T^{-8.99}\end{array}$ & $\begin{array}{l}y=2 \times \\
10^{19} \times T^{-8.46}\end{array}$ & $\begin{array}{l}y=7 \times \\
10^{19} \times T^{-8.96}\end{array}$ & $\begin{array}{l}y=7 \times \\
10^{18 \times T^{-8.29}}\end{array}$ & $\begin{array}{l}y=2 \times \\
10^{19} \times T^{-8.50}\end{array}$ & $\begin{array}{l}y=3 \times \\
10^{17} \times T^{-7.48}\end{array}$ & $\begin{array}{l}y=8 \times \\
10^{16} \times T^{-7.09}\end{array}$ \\
\hline $\begin{array}{l}\text { PAV aged binder } \\
\text { minimum failure } \\
\text { temperature }\end{array}$ & $27.3^{\circ} \mathrm{C}$ & $25.46^{\circ} \mathrm{C}$ & $32.77^{\circ} \mathrm{C}$ & $31.31^{\circ} \mathrm{C}$ & $30.17^{\circ} \mathrm{C}$ & $30.87^{\circ} \mathrm{C}$ & $29.32^{\circ} \mathrm{C}$ & $29.18^{\circ} \mathrm{C}$ & $30.38^{\circ} \mathrm{C}$ & $27.6^{\circ} \mathrm{C}$ & $27.49^{\circ} \mathrm{C}$ \\
\hline $\begin{array}{l}\text { BMA Performance } \\
\text { Grade (PG) }\end{array}$ & PG58 & PG64 & PG64 & PG64 & PG70 & PG70 & PG64 & PG64 & PG70 & PG70 & PG76 \\
\hline
\end{tabular}




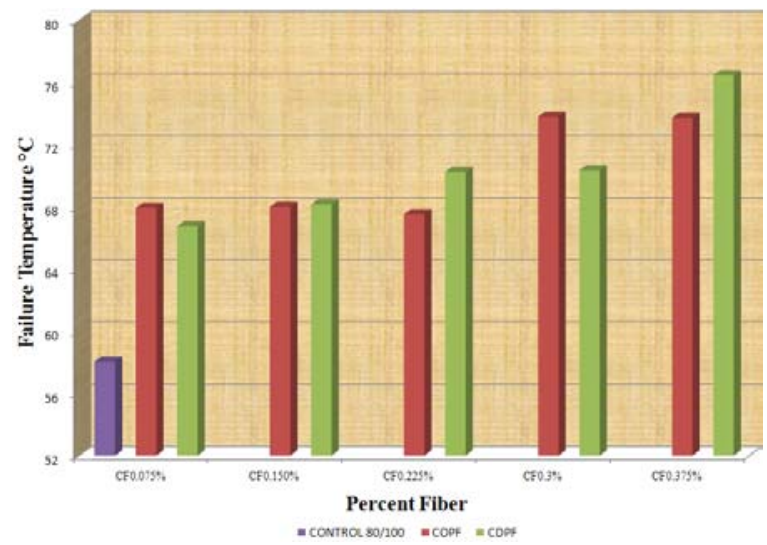

Fig. 7: BMA failure temperature Vs. percent fiber

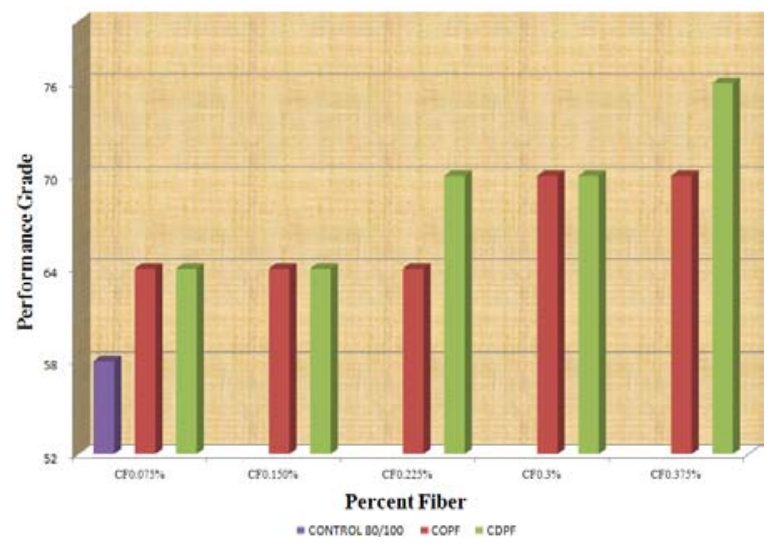

Fig. 8: BMA performance grade Vs. percent fiber

The binder with $0.3 \%$ of oil palm fiber has increased to PG70, by adding the oil palm fiber content up to $0.375 \%$ the performance of the binder does not show enhancement therefore $0.3 \%$ fiber content is recognized to be the optimum fiber content for the oil palm fiber and $0.375 \%$ could be the optimum fiber content for the date palm fiber. Further studies must be carried out to realize if fiber content over $0.375 \%$ for the date palm up to what percentage will be enhancing the rheological properties of the blend but as far as the blending process is concerned, blending fiber content over $0.375 \%$ seem to cause much difficulty because of the low specific gravity of the fluffy fiber.

\section{CONCLUSION}

It is believed that the rheological properties of the $80 / 100$ penetration grade asphalt binder or PG58 could be consolidated by utilizing natural cellulose fibers obtained from date or oil palm EFB. Fiber content of
$0.375 \%$ by the weight of total mix for the date palm fiber improved the blend up to PG 76 and as for the oil palm fiber, fiber content of $0.3 \%$ improved the blend up to PG 70. The date palm fiber showed a better performance rather than the oil palm fiber. Due to high oil prices and eventually higher asphalt cement price and also considering the high price of polymer as a modifier, natural fibers such as date palm cellulose fiber or oil palm cellulose fiber could be used as an alternative to enhance the rheological properties of the binder.

\section{ACKNOWLEDGMENT}

This study is part of a research sponsored by Ministry of Science, Technology and Innovation, Malaysia. The author gratefully acknowledges the financial support provided by the science fund from University Putra Malaysia for funding this study.

\section{REFERENCES}

1. Muniandy, R. and Huat, B.K.H. 2006. Laboratory Diameteral Fatigue Performance of Stone Matrix Asphalt with Cellulose Oil Palm Fiber. American Journal of Applied Sciences 3 (9):2005-2010. Print ISSN 1546-9239 online ISSN 1554-3641. http://www.scipub.org/fulltext/ajas/ajas3920052010.pdf

2. Hassan, H.F. and K.S.A. Jabri, 2005. Effect of organic fibers on open graded friction course mixture properties Int. J. Pave. Eng., 6: 67-75. Print ISSN: 1029-8436 Online ISSN: 1477-268X

3. Sharma, V. and S. Goyal, 2006. Comparative study of performance of natural fibers and crumb rubber modified stone matrix asphalt mixtures. Can. J. Civil Eng., 33 (2): 134-139. doi:10.1139/L05-096.

4. Putman, B.J. and S.N. Amirkhanian, 2004. Utilization of waste fibers in stone matrix asphalt mixtures. Resources, conservation and recycling, 42: 265-274. ISSN 0921-3449.

5. Roberts, F.L., P.S. Kandhal, E.R. Brown, D.Y. Lee and T.W. Kennedy, 1996. Hot Mix Asphalt Matrials, Mixture Design and Construction. NAPA Research and Education Foundation, Second Edition, Lanham, Maryland. ISBN-10: 0914313010, ISBN-13: 978-0914313014.

6. Zaniewski, J.P. and M.E. Pumphrey, 2004. Evaluation of Performance Graded Asphalt Binder Equipment and Testing Protocol. Morgantown, West Virginia: Department of Civil and Environmental Engineering, 2004 April, 2004. http://www2.cemr.wvu.edu/ wwwasph/wvdohrepo rts/binder-eqp.pdf. 